\title{
Christopher Baum: Genetic modification of haematopoietic stem cells: methods and protocols
}

\author{
Humana Press, 2009, HB, 494 pages, £68.99, ISBN: 978-1-58829-980-2
}

\section{Waseem Qasim}

Published online: 14 May 2010

(C) Springer-Verlag 2010

Haematopoietic stem cells are attractive targets for gene therapy. They can be readily harvested from either bone marrow or peripheral blood and manipulated ex vivo. A wave of phase 1 haematopoietic stem cell gene therapy studies using murine retroviral vectors have been reported in the last decade. Though generally successful, unexpected adverse events have been linked to insertional transactivation of protooncogenes and there have been intense efforts to develop safer vector systems. Over the same period, there have been numerous studies involving T-cell gene modification, and interestingly no vector related toxicity has been reported in these trials, probably because of their differentiated nature. The publication of a comprehensive collection of protocols relevant to the expanding field of stem cell and T-cell modification is timely and offers broad coverage from basic vector technology to regulatory issues, both in Europe and North America. Editor Christopher Baum has organised chapters with characteristic logic, beginning with cell isolation techniques and vector technology and extending to setting up relevant animal models and the molecular tracking of transduced cells. The final chapters introduce issues relating to documentation and regulation. Each chapter provides a brief review of the area, followed by a step-by-step guide to undertaking experiments and includes details of reagents required and a list of useful notes or comments of issues that may arise. Comprehensive reference citations provide sources of further information when required. The book should provide a road map for researchers, clinical investigators and regulators involved in modifying haematopoietic cells. 